\title{
MULTIPARTICULATE FLOATING DRUG DELIVERY SYSTEM OF ANAGLIPTIN: DESIGN AND OPTIMIZATION FOR ITS EFFICACY IN MANAGEMENT OF METABOLIC SYNDROME
}

\author{
RAKESH V. MISHRA ${ }^{*}$, SHASHIKANT N. DHOLE ${ }^{2}$
}

1Department of Pharmaceutics, Dr. D. Y. Patil Institute of Pharmaceutical Sciences and Research, Pimpri, Pune 411018, Maharashtra, India, ${ }^{2}$ Department of Pharmaceutics, Modern College of Pharmacy, Moshi, Pune 412105, Maharashtra, India

Email: mishrarakesh287@gmail.com

Received: 27 Mar 2019, Revised and Accepted: 10 May 2019

\section{ABSTRACT}

Objective: The present research aims to design and optimize gastroretentive floating pellets of anagliptin (a dipeptidyl peptidase-4 inhibitor), so as to reduce P-Glycoprotein (PGP)-mediated efflux in the intestine hence to improve oral bioavailability.

Methods: The drug-containing core pellets were prepared by extrusion and spheronization process followed by subsequent coating with three successive layers i.e. Eudragit RS 100, sodium bicarbonate $\left(\mathrm{NaHCO}_{3}\right)$ : hydroxypropyl methylcellulose E5LV (HPMC E5LV) and Eudragit RL 100 using fluidized bed processor. A 3 level 3 factor box-behnken design was adopted to investigate the effect of Eudragit RS 100, $\mathrm{NaHCO}_{3}$ : $\mathrm{HPMC}$ E5LVand Eudragit RL 100 on floating lag time and drug release at $10 \mathrm{~h}$. Desirability function under numerical optimization technique was used to identify the optimum formulation.

Results: The study reveals the significant effect of the amount of $\mathrm{NaHCO}_{3}$ and coating level of polymers on floating lag time and drug release. The optimum system could float within 4 min and exhibited more than $85 \%$ drug release in 10 h. The pharmacokinetic study conducted in male Wistar rats indicated 2.51 fold increase in relative bioavailability of optimized formulation compare to anagliptin drug. Formulated anagliptin pellets were evaluated in cafeteria diet-induced metabolic syndrome model in male Wistar rats. Anagliptin floating pellets treatment compared to cafeteria diet group significantly inhibited increase in body weight $(238.79 \pm 2.52 \mathrm{~g}$ vs. $277.98 \pm 3.69 \mathrm{~g}, \mathrm{P}<0.001)$, calorie intake $(2283.99 \mathrm{kcal}$ vs. $3086.05 \mathrm{kcal}$ $\mathrm{P}<0.05)$ and serum levels of total cholesterol $(95.19 \pm 0.61 \mathrm{mg} / \mathrm{dl}$ vs. $110.04 \pm 1.31 \mathrm{mg} / \mathrm{dl}, \mathrm{P}<0.01)$, triglycerides $(96.12 \pm 1.25 \mathrm{mg} / \mathrm{dl} \mathrm{vs} .105 .99 \pm 1.29$ $\mathrm{mg} / \mathrm{dl}, \mathrm{P}<0.01)$ while high-density lipoproteins levels were improved $(42.15 \pm 0.92 \mathrm{mg} / \mathrm{dl}$ vs. $30.92 \pm 0.77 \mathrm{mg} / \mathrm{dl}, \mathrm{P}<0.01)$ indicated its hypophagic and anti-hyperlipidemic effects.

Conclusion: The gastroretentive floating pellets of anagliptin was obtained and could be a promising technique to deliver anagliptin with improved bioavailability in the management of the metabolic syndrome.

Keywords: Anagliptin, Metabolic syndrome, Floating drug delivery system, Pellets and Spheronization

(C) 2019 The Authors. Published by Innovare Academic Sciences Pvt Ltd. This is an open access article under the CC BY license (http://creativecommons.org/licenses/by/4.0/) DOI: http://dx.doi.org/10.22159/ijap.2019v11i4.33249

\section{INTRODUCTION}

The urbanization and sedentary lifestyles of $21^{\text {st }}$ century leads to increase the prevalence of metabolic syndrome and is becoming a major public health concern. Metabolic syndrome includes the number of chronic disease such as insulin resistance, obesity, dyslipidemia, cardiometabolic risk and hypertension [1]. Patient compliance becomes an issue in the management of metabolic syndrome, due to the use of multiple drugs and risk of enhanced drug-drug interactions [2]. Identifying drug candidates exhibiting polypharmacology could be one of the strategies favourable to deal with multifactorial diseases [3]. Anagliptin a dipeptidyl peptidase 4 (DPP4) inhibitor, besides their glucose-lowering activity, is a promising drug candidate for management of multifactorial diseases constituting metabolic disorders [4]. However, systemic bioavailability of anagliptin is limited by PGP mediated efflux in the intestine [5]. PGP, a plasma membrane-bound ATP-dependent efflux transporter, is a well-recognized factor that can influence drug pharmacokinetics [6]. In addition, anagliptin has a shorter biological halflife of 3-4 h. It is needed to improve the oral bioavailability of anagliptin to be effectively used in many clinical applications. The conventional controlled-release technologies are not suitable for the delivery of PGP substrates because they carry a significant part of the drug to distal regions of the gastrointestinal tract (GIT). On the other hand, continuous delivery to the proximal part of the GIT, as provided by gastroretentive dosage forms, might be useful for these drugs [7-9]. Various approaches have been reported to retain the formulation in the upper part of GIT such as swelling systems, high-density systems, magnetic systems, mucoadhesive systems and floating systems [10]. Among all the gastroretentive systems, due to minimum effect on GIT motility, floating drug delivery systems (FDDS) are considered suitable and preferable [11-13]. These systems are particularly useful for drugs having absorption in upper GIT, drugs which are unstable in the intestine and exhibits poor solubility in intestinal pH [14]. FDDS are low density system which allows them to remain buoyant over gastric content for prolonged period of time [15]. Based upon the mechanism of buoyancy effervescent systems are the widely employed technique used in the development of FDDS. In the effervescent systems, carbon dioxide gas liberation occurs upon contact with gastric fluid due to neutralization reaction which lowers the density and allows the system to remain buoyant [16]. A wide range of single unit and multiparticulate FDDS were designed and developed, the multiparticulate FDDS were preferred over single unit system due to reduce inter and intra subject variabilities in drug absorption and lower possibility of dose dumping [17-19]. Designing sustained release multiparticulate drug delivery system of anagliptin with prolonged residence time in the stomach using FDDS approach can significantly improve the overall bioavailability.

In the present investigation, a floating multiparticulate drug delivery system of anagliptin based on effervescent technique was developed. The drug-containing core pellets were prepared using extrusion and spheronization process. The drug-loaded pellets were coated with three successive layers, internal coat of Eudragit RS 100 as release retardant followed by effervescent layer coat $\left(\mathrm{NaHCO}_{3}\right.$ : HPMC E5LV); and top coat of Eudragit RL 100 as a gas entrapped polymeric membrane. The effect of the amount of effervescent agent and coating level of polymeric membrane on floating ability and drug release properties were studied and optimized using response surface methodology.

\section{MATERIALS AND METHODS}

\section{Materials}

Anagliptin was obtained as gift sample from Wockhardt Limited, Aurangabad, India. Eudragit RL 100 and Eudragit RS 100 were provided by Evonik Pharma, Mumbai, India. Sodium bicarbonate, Hydroxypropyl 
methylcellulose E5LV, Microcrystalline cellulose, polyvinylpyrrolidone K30 obtained from Himedia Laboratories, Mumbai, India. All the other reagents used in the study were of analytical grade.

\section{Preparation of gastroretentive floating pellets \\ Preparation of drug loaded pellets}

The anagliptin containing core pellets were prepared using wet granulation method by extrusion and spheronization technique. Powder mixture of anagliptin $(40 \% \mathrm{w} / \mathrm{w})$ and spheronizing aid (microcrystalline cellulose $60 \% \mathrm{w} / \mathrm{w}$ ) was mixed uniformly in mortar for 20 min. This was followed by the addition of binding liquid $(0.5 \% \mathrm{w} / \mathrm{v}$ polyvinylpyrrolidone $\mathrm{K} 30$ in distilled water) into the dry powder mixture. Binding liquid was incorporated into the pelletization process to get damp mass and to obtain sufficient hardened pellets suitable for the subsequent coating process. The prepared damp mass was passed through BSS sieve no.16 to get the extrudates. Extrudates were then transferred to spheronizer (Shakti Pharmatech, Ahmedabad, India) and spheronized at 900rpm for about $10 \mathrm{~min}$ to obtain the pellets. The drug-loaded core pellets were oven dried overnight at $40^{\circ} \mathrm{C}$.

\section{Coating of drug loaded pellets}

The drug-loaded pellets were coated with three successive layers, release retardant Eudragit RS 100 as internal coat followed by effervescent layer $\left(\mathrm{NaHCO}_{3}\right.$ : HPMC E5LV) and gas entrapped Eudragit RL 100 as top coat. The Eudragit RS 100 coating solution was prepared by dissolving it into isopropyl alcohol $(10 \% \mathrm{w} / \mathrm{w}$ solid content) plasticized with $10 \%$ triethyl citrate (w/w based on polymer solid) and stirred to obtain a clear solution. The coating process was conducted in fluidized bed processor (ACG, Miniquest-F, Mumbai, India), to obtain predetermined weight gain of $5 \%, 10 \%$ and $15 \% \mathrm{w} / \mathrm{w}$. The coating conditions were batch size, $10 \mathrm{~g}$; inlet temperature, $40^{\circ} \mathrm{C}$; product temperature, $35^{\circ} \mathrm{C}$; air flow, $0.8-1.0$ bar; spray pressure, $0.5-0.9$ bar; spray rate, $4-5 \mathrm{ml} / \mathrm{min}$ and final drying at $40^{\circ} \mathrm{C}$ for $15 \mathrm{~min}$. The Eudragit RS 100 coated pellets were further coated with effervescent layer coating. The required amount of $\mathrm{NaHCO}_{3}$ was dispersed in HPMC E5 LV solution $10 \% \mathrm{w} / \mathrm{w}$ solid content in the ratio of 2:1, 1:1 and 1:2(w/w), plasticized with $10 \%$ Polyethylene glycol 6000 (w/w based on polymer solid). The effervescent layer coating was done to obtain a fixed weight gain of $10 \% \mathrm{w} / \mathrm{w}$. The coating conditions were temperature, $40^{\circ} \pm 5^{\circ} \mathrm{C}$; air flow, 0.8-1.0 bar; spray pressure, $0.5-0.9$ bar; spray rate, 1-1.5 $\mathrm{ml} / \mathrm{min}$. The obtained effervescent layered coated pellets were dried at $40^{\circ} \mathrm{C}$ for $30 \mathrm{~min}$. Finally, Eudragit RL 100 coating solution prepared in Isopropyl alcohol (10\% w/w solid content) plasticized with $10 \%$ triethyl citrate ( $w / w$ based on polymer solid) coated over effervescent layered pellets. During coating the predetermined weight gain obtained was $5 \%, 10 \%$ and $15 \% \mathrm{w} / \mathrm{w}$. The coating conditions were the same as kept during coating of Eudragit RS 100 mentioned above. The formulation batches prepared are indicated in table 2 .

\section{Experimental design}

A 3-level, 3-factor, 13 run experiment box-behnken design was adopted for optimization of gastroretentive floating pellets formulations. The selected independent variables were the concentration of Eudragit RS 100 (X1), the ratio of $\mathrm{NaHCO}_{3}$ : HPMC (X2) and Eudragit RL 100 concentration (X3). The levels of independent variables are shown in (table 1). The dependent variables taken as a response were floating lag time (Y1) and percent drug release in $10 \mathrm{~h}$ (Y2). The experimental formulations composition indicated in (table 2). Response surface modelling, ANOVA and model graphs studies were carried out employing Design-expert ${ }^{\circledR}$ software (Version10, Stat-Ease).

Table 1: Levels of independent variables in experimental design

\begin{tabular}{llllll}
\hline Factors & \multicolumn{2}{l}{ Coded value } & \multicolumn{2}{l}{ Actual value } \\
\cline { 2 - 5 } & Low & Medium & High & Low & Medium \\
\hline Eudragit RS 100 (\%)-X1 & -1 & 0 & +1 & 05 & 10 \\
NaHCO $_{3}$ : HPMC (\%)-X2 & -1 & 0 & +1 & $1: 2$ & $1: 1$ \\
Eudragit RL 100 (\%)-X3 & -1 & 0 & +1 & 05 & 10 \\
\hline
\end{tabular}

Table 2: Experimental formulation composition

\begin{tabular}{|c|c|c|c|}
\hline Batch No. & Eudragit RS 100 (\%) & $\mathrm{NaHCO}_{3}:$ HPMC (\%) & Eudragit RL 100 (\%) \\
\hline F 1 & 10 & $2: 1$ & 15 \\
\hline F 2 & 10 & $1: 1$ & 10 \\
\hline F 3 & 05 & $1: 1$ & 15 \\
\hline F 4 & 05 & $1: 1$ & 05 \\
\hline F 5 & 10 & $1: 2$ & 05 \\
\hline F 6 & 05 & $2: 1$ & 10 \\
\hline F 7 & 05 & $1: 2$ & 10 \\
\hline F 8 & 15 & $1: 2$ & 10 \\
\hline F 9 & 15 & $1: 1$ & 15 \\
\hline F 10 & 10 & $2: 1$ & 05 \\
\hline F 11 & 15 & $2: 1$ & 10 \\
\hline F 12 & 10 & $1: 2$ & 15 \\
\hline F 13 & 15 & $1: 1$ & 05 \\
\hline$F 14$ & 05 & $2: 1$ & 05 \\
\hline
\end{tabular}

The desirability approach was used in Design-expert ${ }^{\circledR}$ software to find the optimum level of independent variables, to gainsay the reliability suggested new formulation was prepared (batch F 14).

\section{Evaluation of gastro retentive floating pellets}

\section{Physical characterization}

The micromeritic properties (Carr's index, Hausner's ratio and angle of repose) were determined to evaluate the flow properties of floating pellets. Friability of the pellet formulations was determined using friabilator (Veggo Friability Tester, India). $10 \mathrm{~g}$ of core pellets were kept into friabilator and the percentage weight loss after 200 revolutions was determined to calculate friability [20-23].

\section{Pellet sphericity}

Pellets sphericity was determined in terms of aspect ratio [24]. Feret diameter and perpendicular diameter of the pellet were measured using digital vernier calliper (Mitutoyo, Japan). The aspect ratio of pellets was calculated with the following equation:

$$
\text { Aspect Ratio }=\frac{\text { Feret diameter }}{\text { Perpendicular diameter }}
$$




\section{Determination of the drug content}

The drug content in the floating pellets formulation was determined by extraction with $0.1 \mathrm{~N} \mathrm{HCl}$. Pellets equivalent to about $200 \mathrm{mg}$ of anagliptin were accurately weighed, ground and transferred into a volumetric flask containing $0.1 \mathrm{~N} \mathrm{HCl}$. The mixture was sonicated for 30 min to ensure complete extraction of the drug. The solution was further filtered, diluted with an appropriate amount of $0.1 \mathrm{~N} \mathrm{HCl}$ and assayed spectrophotometrically at $248.5 \mathrm{~nm}$ (Shimadzu, 1700, Japan). The analysis was performed in the range of $0-10 \mu \mathrm{g} / \mathrm{ml}$ where Beer's law was obeyed for anagliptin.

\section{Scanning electron microscopy (SEM)}

The surface morphology of the uncoated pellets, Eudragit RS 100 coated, effervescent layer coated and Eudragit RL 100 coated pellets were examined under the scanning electron microscope (Jeol, Oxford Instrument, United Kingdom). The pellet samples were sputter coated with gold/Palladium mixture for $1 \mathrm{~min}$ under an argon atmosphere and placed into a scanning electron microscope chamber. The photomicrograph of the pellets was obtained at $20 \mathrm{kV}$ accelerating voltage.

\section{Floating studies}

The floating studies were conducted using USP Type-II dissolution apparatus (Veego DA-8D, India) in $900 \mathrm{ml}$ of $0.1 \mathrm{~N} \mathrm{HCl}$ maintained at $37^{\circ} \mathrm{C} \pm 0.5^{\circ} \mathrm{C}$. The medium was agitated by paddle at $50 \mathrm{rpm}$ into which coated pellets (100) were placed [25-27]. The time taken by the pellets to rise over the surface of the medium (floating lag time) was measured visually $(n=3)$. The floating pellets percentage at $10 \mathrm{~h}$ was also determined by the equation indicated below:

$$
\text { Floating pellets }(\%)=\frac{\text { No.of floating pellets at measure time }}{\text { Initial no.of pellets }} \times 100
$$

\section{In vitro drug release study}

In vitro drug release study of anagliptin (uncoated and coated pellet formulations) was determined in triplicates using USP Type-II dissolution apparatus (Veego DA-8D, India). The dissolution medium used was $900 \mathrm{ml}$ of $0.1 \mathrm{~N} \mathrm{HCl}$. Pellets equivalent to $200 \mathrm{mg}$ of anagliptin were accurately weighed and transferred into dissolution medium kept at $37^{\circ} \mathrm{C} \pm 0.5^{\circ} \mathrm{C}$ on $50 \mathrm{rpm}$. At predetermined time intervals, $5 \mathrm{ml}$ of aliquots were withdrawn and immediately replaced by the same volume of fresh medium to maintain the sink condition. The aliquots were filtered and analyzed by UV spectrophotometer at $248.5 \mathrm{~nm}$ to calculate the drug release.

To understand the mechanism of drug release kinetics from optimized floating pellets formulation, the obtained drug release data were analyzed according to the mathematical models like zeroorder model, first-order model, Higuchi model and KorsmeyerPeppas model [28-32].

\section{Statistical data analysis and optimization}

The obtained data of responses (floating lag time and percentage drug release at $10 \mathrm{~h}$ ) for all formulations were analyzed by Designexpert ${ }^{\circledR}$ software. Polynomial models for all the response variables including linear, interaction and quadratic terms were generated. The suggested model based upon the values of standard deviation, multiple correlation coefficient $\left(\mathrm{R}^{2}\right)$ and adjusted multiple correlation coefficient (adjusted $\mathrm{R}^{2}$ ) was selected [33]. The selected model was further analyzed by analysis of variance (ANOVA) to determine significant model terms. The $P$ value, lack of fit value, regression equation of the responses, diagnostic plot (Actual vs Predicted) and response surface plots were also generated using the software. The generated response surface plots were studied to understand the relationship between the dependent and independent variables. Finally, a numerical optimization technique based upon desirability approach was used to determine the optimum level of independent variables for the formulation.

\section{Stability studies}

The accelerated stability study of anagliptin floating pellet formulation was performed as per ICH guidelines. The pellet sample was stored in $10 \mathrm{ml}$ open glass vials at $40^{\circ} \mathrm{C} / 75 \%$ relative humidity for three months. Pellet sample was observed for drug content, drug release at $10 \mathrm{~h}$ and any change in physical appearance after first, second and third month [34].

\section{In vivo pharmacokinetics-study design}

In vivo pharmacokinetics studies were conducted in male Wistar rats after obtaining approval from the Institutional Animal Ethical Committee (DYPIPSR/IAEC/MAY/17-18/P-16). The study was aimed to compare the formulated anagliptin floating pellets with anagliptin plain drug. Twelve wistar rats weighing 180-200 g were separated randomly into two groups and fasted overnight with free access to water. Anagliptin floating pellets $(200 \mathrm{mg} / \mathrm{kg})$ and anagliptin plain drug $(200 \mathrm{mg} / \mathrm{kg})$ were administered orally into respective groups. At predetermined time intervals $(0.25,0.5,1,2,4,8,12$, and $24 \mathrm{~h})$ post oral dose, $0.5 \mathrm{ml}$ of blood samples were collected by the retro-orbital method. Plasma was immediately separated by centrifuging at 4000 rpm for $15 \mathrm{~min}$ and stored at $-20^{\circ} \mathrm{C}$ until analysis.

\section{HPLC analysis of anagliptin in plasma}

Plasma concentrations of anagliptin were determined by HPLC method [5]. To $0.1 \mathrm{ml}$ of plasma sample, $0.9 \mathrm{ml}$ of acetonitrile was added and centrifuged for $15 \mathrm{~min}$ at $10000 \mathrm{rpm}$. The supernatant liquid obtained after centrifugation was filtered through $0.2 \mu$ filter followed by injection of $20 \mu$ into the system. The chromatography was carried out on a reversed-phase HPLC column (Kromasil, $4.6 \mathrm{x}$ $250 \mathrm{~mm}, 5 \mathrm{um}$, Shreetech Associates; Mumbai, India) using Shimadzu HPLC LC20 AD (Shimadzu Corporation, Japan). The mobile phase consisted of acetonitrile and ammonium acetate buffer $\mathrm{pH} 4.5$ (50:50). The eluate was analyzed at a wavelength of $248 \mathrm{~nm}$ with a flow rate of $0.8 \mathrm{ml} / \mathrm{min}$.

\section{Pharmacokinetic analysis}

Required pharmacokinetic parameters were calculated using PK solver software (version 2.0). Peak plasma concentration (Cmax), time to reach peak plasma levels (Tmax), area under the curve (AUC), mean residence time (MRT), half-life (t1/2), elimination constant (Kel) and relative bioavailability were estimated. The calculated pharmacokinetic parameters of both anagliptin floating pellets and plain drug were statistically analyzed using ANOVA and the difference less than the probability level 0.05 was considered statistically significant.

Table 3: Calorie value of the cafeteria diet

\begin{tabular}{ll}
\hline Ingredients & Calorie Value (Kcal/100g) \\
\hline Condensed Milk & 69 \\
Bread & 247 \\
Chocolate & 230 \\
Biscuits & 453 \\
Dried Coconut & 185 \\
Cheese & 402 \\
Boiled Potato & 75 \\
\hline
\end{tabular}

Pharmacodynamic study in cafeteria diet-induced metabolic syndrome model

The male Wistar rats (180-200 g) were procured from National Institute of Bio-science, Pune, Maharashtra, India. The animals were housed under controlled room temperature and humidity condition with $12 \mathrm{~h}$ light and $12 \mathrm{~h}$ dark cycle. The animals were provided free access to food and water. After one week of acclimatisation period, animals were used for the study. The experimental protocol was approved by the Institutional Animal Ethical Committee 
(DYPIPSR/IAEC/MAY/17-18/P-17). In the present study cafeteria diet (CD) induced metabolic syndrome model in rats is selected as they more resemble to human ultra-processed diet compared to commercial high-fat or high-sugar rodent diets $[35,36]$. The CD composed of condensed milk (8g), bread ( $8 \mathrm{~g})$, chocolate $(3 \mathrm{~g})$, biscuits $(6 \mathrm{~g})$, dried coconut $(6 \mathrm{~g})$, cheese $(8 \mathrm{~g})$ and potato chips $(10$ g). These diets were provided to the individual rats of group II to IV during the $42 \mathrm{~d}$ of the experiment. The calorie value of the $\mathrm{CD}$ indicated in (table 3).

\section{Experiment protocol}

The study includes 24 rats divided into four groups of 06 rats each. The drugs were administered through per oral (p. o.) route using oral gavage once a day for a period of $42 \mathrm{~d}$.

Group I: Normal control fed with rodent chow diet and 0.5\% CMC.

Group II: Fed with Cafeteria Diet.

Group III: Cafeteria diet+Orlistat ( $45 \mathrm{mg} / \mathrm{kg}$, p. o.) in $0.5 \% \mathrm{CMC}$ from $8^{\text {th }}$ day.

Group IV: Cafeteria diet+Anaglitin floating pellet formulation (200 $\mathrm{mg} / \mathrm{kg}$, p. o.) from $8^{\text {th }}$ day.

The food intake of each animal group was measured by calculating the difference in weight of preweighed chows and the food remain over after $24 \mathrm{~h}$. The daily caloric (kcal) intake was determined by multiplying the food intake by their caloric content and expressed as mean energy intake for a group of six rats in $\mathrm{kcal} /$ week. The body weights of the rats from each group were taken separately on $0^{\text {th }}$, $7^{\text {thand }} 42^{\text {nd }}$ day. Body mass index (BMI) was calculated from formula: BMI = body weight $(\mathrm{g}) / \mathrm{length}^{2}\left(\mathrm{~cm}^{2}\right)$. On $43^{\text {rd }}$ day animals were anesthetized with ether to collect the blood by the retro-orbital method. Serum was immediately separated by centrifuging at 4000 rpm for $15 \mathrm{~min}$. The serum levels of glucose, total-cholesterol $(\mathrm{CH})$, high-density protein (HDL), low-density protein (LDL), triglycerides (TGs), Alanine Aminotransferase (ALT) and Aspartate Aminotransferase (AST) were estimated using the biochemical kits (Pathozyme Diagnostics). After collection of blood, rats were sacrificed; organs viz; liver, heart and white adipose tissue (WAT) were excised immediately, rinsed with phosphate buffer saline and weighed.

\section{Statistical analysis}

Data were expressed as the mean \pm standard error of the mean (SEM). The results were analyzed by one way or two way ANOVA (analysis of variance) followed by Bonferroni test using Graph pad prism-7 software. Values of $\mathrm{P}<0.05$ were considered significant.

\section{RESULTS AND DISCUSSION}

\section{Design of gastroretentive floating pellets}

The floating system consisted of drug loaded pellets coated with three successive layers, release retardant Eudragit RS 100 as internal coat over which $\mathrm{NaHCO}_{3}$ : HPMC E5LV layered as effervescent coat and gas entrapped Eudragit RL 100 as top coat indicated in (fig. 1). The prepared floating pellets were based on gas formation technique which upon contact with gastric fluid liberates carbon dioxide $\left(\mathrm{CO}_{2}\right)$ due to the neutralization of $\mathrm{NaHCO}_{3}$. The liberated $\mathrm{CO}_{2}$ gets entrapped into the outer polymeric membrane and generates sufficient buoyancy to make the pellets float. The outer polymeric membrane should be highly water permeable so as to initiate the effervescent reaction and the floating process more rapidly. To maintain the flotation the hydrated coat should also be flexible to avoid rupturing and impermeable to the generated $\mathrm{CO}_{2}$ [37]. Due to these reasons the higher flexible, water permeable and gas impermeable Eudragit RL 100 was chosen as a gas entrapped outer polymeric membrane. During effervescent layer coating as $\mathrm{NaHCO}_{3}$ itself is not sticky, HPMC E5 LV was used as binder to allow adherence of $\mathrm{NaHCO}_{3}$ on to the pellets. The solubility of anagliptin is higher in acidic media, it was difficult to sustain the release with
Eudragit RL 100 and a release retarding polymer layer was required. Eudragit RS 100 was investigated as release retardant internal polymeric coat due to its lower hydrophilicity which makes it less water permeable. To develop an optimal formulation i.e. having minimum floating lag time and maximum drug release in $10 \mathrm{~h}$, the parameters such as the concentration of Eudragit RS 100, the ratio of $\mathrm{NaHCO}_{3}$ : HPMC and Eudragit RL 100 concentration were varied and evaluated in the study.

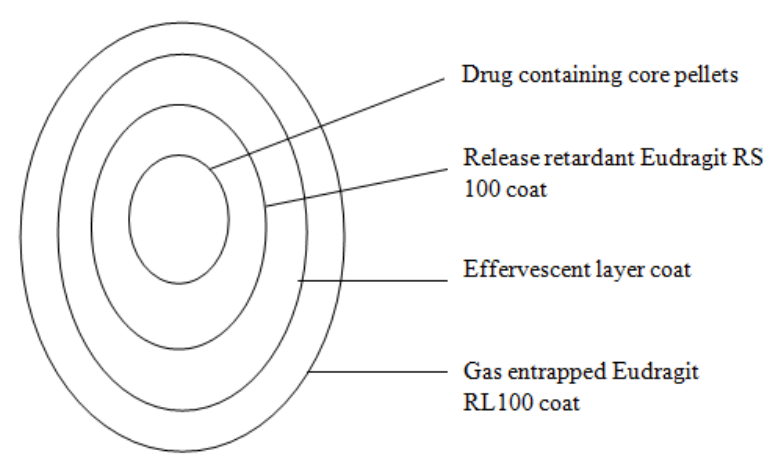

Fig. 1: Design of gastroretentive floating pellets

\section{Evaluation of gastroretentive floating pellets}

\section{Physical characterization}

To evaluate the flow properties of floating pellet formulations, Carr's index, Hausner's ratio and angle of repose were determined. The Carr's index and Hausner's ratio ranged from $5.22 \pm 0.31 \%$ to 14.16 $\pm 0.15 \%$ and $1.05 \pm 0.1$ to $1.12 \pm 0.21$ respectively. The values obtained for the angle of repose were in the range of $23.5^{\circ} \pm 0.27^{\circ}$ to $26.12^{\circ} \pm 0.32^{\circ}$. The obtained data of micromeritic properties indicated good flow behavior of pellet formulation. The friability of the pellets formulation ranged from $0.24 \pm 0.11 \%$ to $0.51 \pm 0.08 \%$. The results of friability study showed that the prepared core pellets were quite hard and suitable for the subsequent coating process.

\section{Pellet sphericity}

Sphericity of the pellets is an essential property to obtain effective coating. The spherical shape pellets provides uniform surface during the coating process. Sphericity of the pellets was determined in terms of aspect ratio. The aspect ratio values equal to unity indicate the spherical shape of pellets [24]. The prepared core pellets showed aspect ratio values in the range of $0.98 \pm 0.01$ to $1.09 \pm 0.05$.

\section{Drug content}

The drug content in all the floating pellet formulation was determined by UV spectroscopy method. It was found to be between $96.23 \pm 0.5 \%$ to $98.75 \pm 0.41 \%$ which indicated that the multilayering coating on the pellets was uniform and it does not affect the drug content.

\section{Scanning electron microscopy (SEM)}

Surface morphology of the uncoated and coated pellets are shown in (fig. 2). Fig. 2. (A) shows the surface of drug-containing uncoated pellets. The uncoated pellets exhibit rough external appearance. fig. 2. (B) Eudragit RS 100 coated pellets shows the spherical shape and smooth surface. The effervescent layer coating over Eudragit RS 100 coated pellets produce pellets with a slight smooth surface as indicated in fig. 2. (C). This may occur due to the layering of $\mathrm{NaHCO}_{3}$ dispersion (prepared in HPMC E5 LV solution). The top coat of Eudragit RL 100 as gas entrapped polymer coating (complete floating pellets) produces pellets with the smoothest surface shown in fig. 2. (D). 

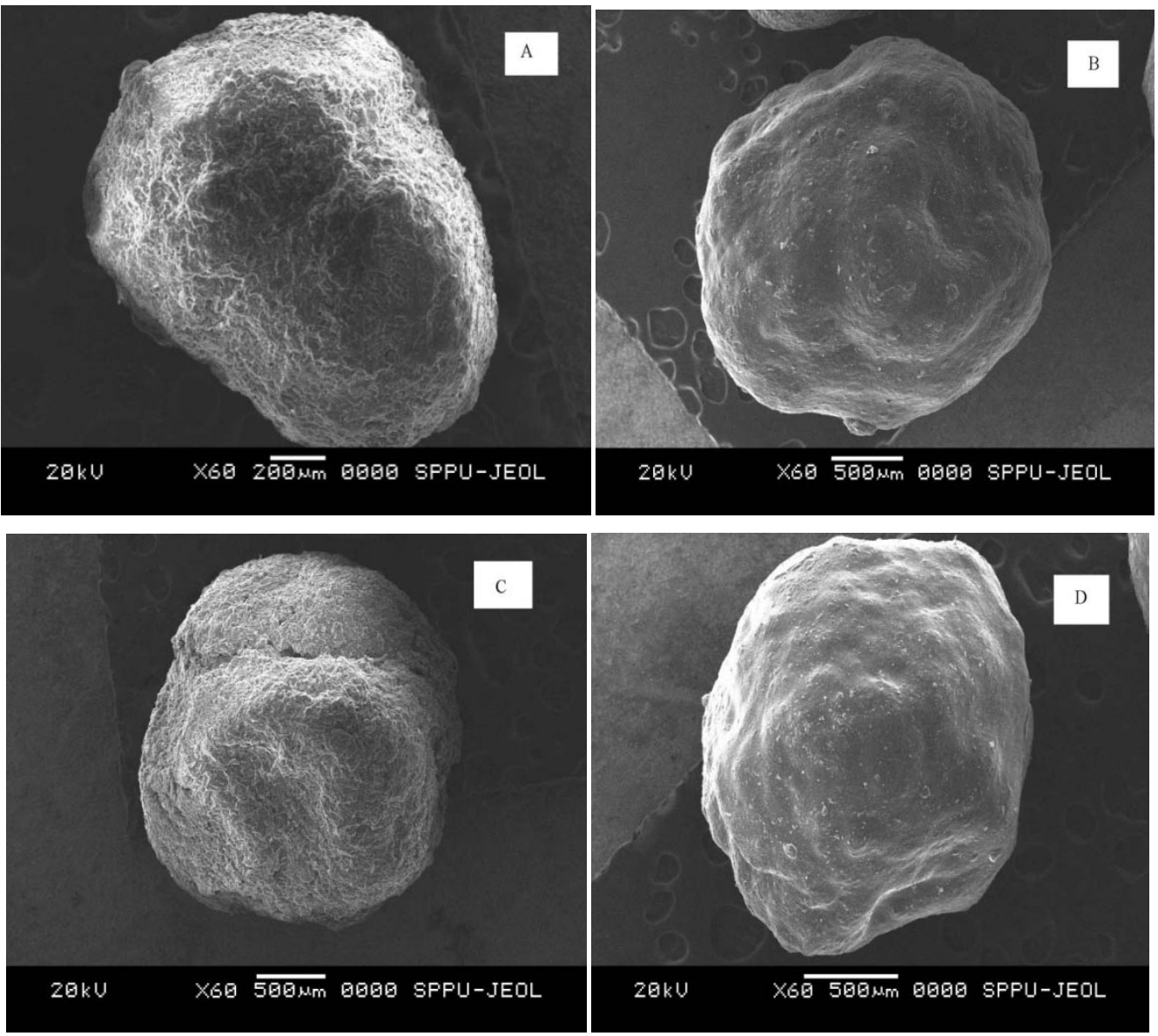

Fig. 2: Scanning electron microphotographs of (A) Drug loaded uncoated pellets, (B) Pellets coated with release retardant (5\% Eudragit RS 100), (C) Effervescent layered ( $\mathrm{NaHCO}_{3}: \mathrm{HPMC}^{2}: 1 \mathrm{w} / \mathrm{w}$ ) coat over Eudragit RS 100 coat, (D) Gas entrapped complete floating pellets (5\% Eudragit RL 100)

\section{Floating studies}

The prepared anagliptin pellets was studied for gastro-floating behaviour in $0.1 \mathrm{~N} \mathrm{HCl}$. Floating lag time and the percentage of pellets floating at $10 \mathrm{~h}$ were determined. An ideal floating system after contact with gastric fluid should float in few seconds to avoid the formulation from transiting into small intestine [18]. The data obtained with floating studies revealed that the floating behaviour is significantly affected by the amount of effervescent agent $\left(\mathrm{NaHCO}_{3}\right.$ : HPMC ratio) and level of gas entrapped polymeric coating (Eudragit RL 100). In the present study the amount of effervescent layer coating was kept constant $(10 \% \mathrm{w} / \mathrm{w})$ and ratio of $\mathrm{NaHCO}_{3}$ : HPMC was varied. The floating lag time observed for all pellet formulation was in the range of 3 to 35 min shown in (table 4). As the amount of $\mathrm{NaHCO}_{3}$ in effervescent layer coating increases and the level of
Eudragit RL 100 coat decreases, the floating lag time gets decreased. This behaviour could be explained as, with lower level of Eudragit RL 100 coat the acidic media can quickly penetrates into the system and initiate effervescent reaction more rapidly. On the other side the lower level of Eudragit RL 100 with lower level of $\mathrm{NaHCO}_{3}$ unable to produce pellets with minimum floating lag time. This could be attributed due to the reduced amount of $\mathrm{NaHCO}_{3}$ with lower level of Eudragit RL 100 coat, the medium penetration was rapid but unable to generate sufficient $\mathrm{CO}_{2}$ to provide buoyancy. The percentage of pellets floating at $10 \mathrm{~h}$ ranged from $70 \%$ to $92 \%$ for all pellet formulation as shown in (fig. 3). The pellet formulations prepared with lower level of Eudragit RL 100 and higher level of effervescent agent also shows about $75 \%$ floating at $10 \mathrm{~h}$. This indicated that even the lower amount of Eudragit RL 100 used in the study was sufficient to entrap the generated $\mathrm{CO}_{2}$ and can maintain the floating for upto $10 \mathrm{~h}$.

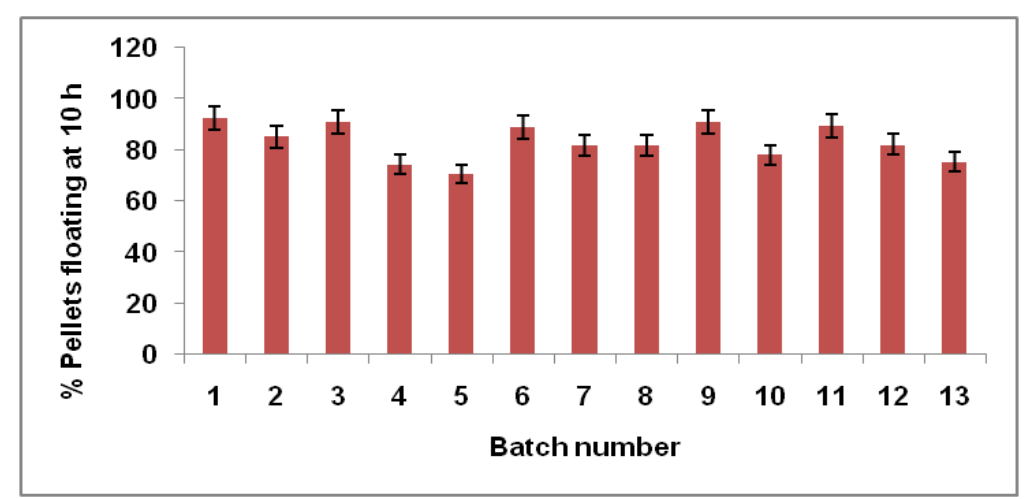

Fig. 3: Percentage pellets floating at $10 \mathrm{~h}$ of batches F 1 to F 13 mean $\pm S D ; n=3$ 


\section{In vitro drug release study}

The in vitro release profile of anagliptin uncoated and coated floating pellet formulations were studied indicated in (fig.4). The uncoated anagliptin pellets showed about $80 \%$ drug release in $1 \mathrm{~h}$. In the preliminary study the release profile of floating pellets (without Eudragit RS 100 release retardant coat) was also studied. Even the higher level of Eudragit RL 100 coat (15\%) system also gives more than $75 \%$ drug release in less than $2 \mathrm{~h}$ (data not shown), indicated Eudragit RL 100 alone unable to sustain the drug release. Afterward, it was decided to investigate Eudragit RS 100 as release retardant internal polymer layer to obtain sustain drug release for $10 \mathrm{~h}$. As the amount of Eudragit RS 100 was increased the drug release was decreased. The result indicated that with increasing polymer layer thickness, medium penetration reduces leading to decreased drug release. However, no significant difference in drug release was observed by varying the amount of effervescent agent. The in vitro release studies reveals that with lower level of Eudragit RS 100 (5 $\%$ ) as release retardant, maximum drug release (about $85 \%$ ) can be obtained in $10 \mathrm{~h}$.

Table 4: Response data of batches F1-F14

\begin{tabular}{lll}
\hline Batch No. & Floating lag time (min) $\mathbf{Y}_{\mathbf{1}}$ & Average drug release in 10 h (\%) $\mathbf{Y}_{\mathbf{2}}$ \\
\hline F1 & $9.8 \pm 1.7$ & $64.79 \pm 0.21$ \\
F 2 & $17.9 \pm 2.1$ & $68.58 \pm 0.15$ \\
F 3 & $21.2 \pm 2.4$ & $75.86 \pm 0.29$ \\
F 4 & $13.4 \pm 1.3$ & $84.88 \pm 0.34$ \\
F 5 & $25.6 \pm 2.5$ & $73.78 \pm 0.41$ \\
F 6 & $6.4 \pm 1.9$ & $79.85 \pm 0.23$ \\
F 7 & $29.2 \pm 1.5$ & $80.19 \pm 0.26$ \\
F 8 & $29.4 \pm 3.2$ & $56.24 \pm 0.33$ \\
F 9 & $20.9 \pm 2.8$ & $52.23 \pm 0.37$ \\
F 10 & $3.6 \pm 1.2$ & $73.29 \pm 0.22$ \\
F 11 & $6.2 \pm 1.4$ & $55.79 \pm 0.23$ \\
F 12 & $33.6 \pm 2.5$ & $65.57 \pm 0.24$ \\
F 13 & $13.2 \pm 1.6$ & $59.71 \pm 0.43$ \\
F 14 & $3.4 \pm 1.5$ & $86.54 \pm 0.35$ \\
\hline
\end{tabular}

mean $\pm S D ; n=3$

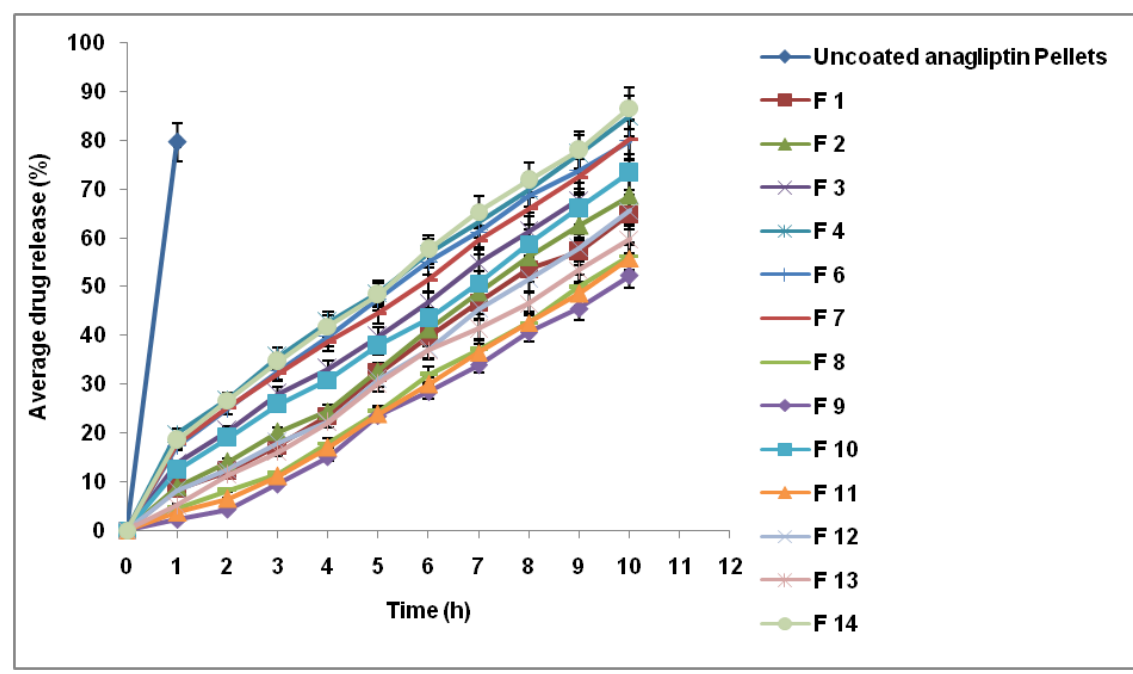

Fig. 4: In vitro dissolution study of uncoated and floating pellet formulations (batch F 1-F 14) mean \pm SD; $n=3$

Drug release data of floating pellets formulation (batch F 14) was analyzed according to various mathematical models to understand the drug release kinetics. The regression coefficients $\left(R^{2}\right)$ obtained from various models shown in (table 5). The $\mathrm{R}^{2}$ value was used as an indicator of the best fitted model suggested that the drug release follows either zero-order or Higuchi's model. Both dissolution and diffusion from the surface of pellets were responsible for initial slight fast release. As the drug depleted in the outer zone, the drug particles in the inner area diffused with a slower rate through the coated polymer layer.

Table 5: Regression coefficients of various mathematical models

\begin{tabular}{lllll}
\hline Batch No. & Zero-order & First order & Higuchi release & Korsmeyer-peppers \\
\hline F 14 & 0.9977 & 0.9811 & 0.9906 & 0.9899 \\
\hline
\end{tabular}

\section{Statistical data analysis and optimization}

The responses obtained (floating lag time and drug release in $10 \mathrm{~h}$ ) for 13 batches were fitted into the various model using design expert software. A quadratic model is suggested for both the responses accordingly ANOVA for response surface quadratic model was generated indicated in (table 6). For the model to fit well with the experimental design the model p-value should be significant and the lack of fit should be insignificant [33]. The model F value and Prob $>F$ values (less than 0.05 ) obtained for both the responses indicated that 
the model terms are significant. Lack of fit for both the response was found to be not-significant indicated that the selected model can be suitably studied further for response surface plots. The ANOVA results suggested that for floating lag time (coded units $B, C, A^{2}, B^{2}, C^{2}$ and $B C$ ) and drug release (coded units $\mathrm{A}, \mathrm{C}, \mathrm{A}^{2}$ and $\mathrm{C}^{2}$ ) are significant model terms (A: Eudragit RS 100; B: $\mathrm{NaHCO}_{3}$ : HPMC and C: Eudragit RL 100).
The values of $\mathrm{SD}, \mathrm{CV}, \mathrm{R}^{2}$, adjusted $\mathrm{R}^{2}$ and predicted $\mathrm{R}^{2}$ are shown in (table 7). For both the responses the predicted $R^{2}$ value is in reasonable agreement with adjusted $\mathrm{R}^{2}$ value. Adequate precision measures signal to noise ratio ( $>4$ desirable). In both responses the adequate precision was greater than 4 indicating an adequate signal and the model can be used to navigate the design space.

Table 6: Summary of ANOVA results for response surface quadratic model

\begin{tabular}{|c|c|c|c|c|c|c|}
\hline Parameter & Sum of squares & Degrees of freedom & Mean square & F value & P value Prob $>F$ & Remark \\
\hline \multicolumn{7}{|c|}{ Floating lag time } \\
\hline Model & 1167.04 & 9 & 129.67 & 2951.87 & $<0.0001$ & significant \\
\hline Residual & 0.31 & 7 & 0.044 & & & \\
\hline Lack of Fit & 0.25 & 3 & 0.083 & 5.50 & 0.0666 & not-significant \\
\hline Pure Error & 0.060 & 4 & 0.015 & & & \\
\hline \multicolumn{7}{|c|}{ Drug Release in $10 \mathrm{~h}$} \\
\hline Model & 1314.87 & 9 & 146.10 & 1131.47 & $<0.0001$ & significant \\
\hline Residual & 0.90 & 7 & 0.13 & & & \\
\hline Lack of Fit & 0.11 & 3 & 0.037 & 0.19 & 0.8986 & not-significant \\
\hline Pure Error & 0.79 & 4 & 0.20 & & & \\
\hline
\end{tabular}
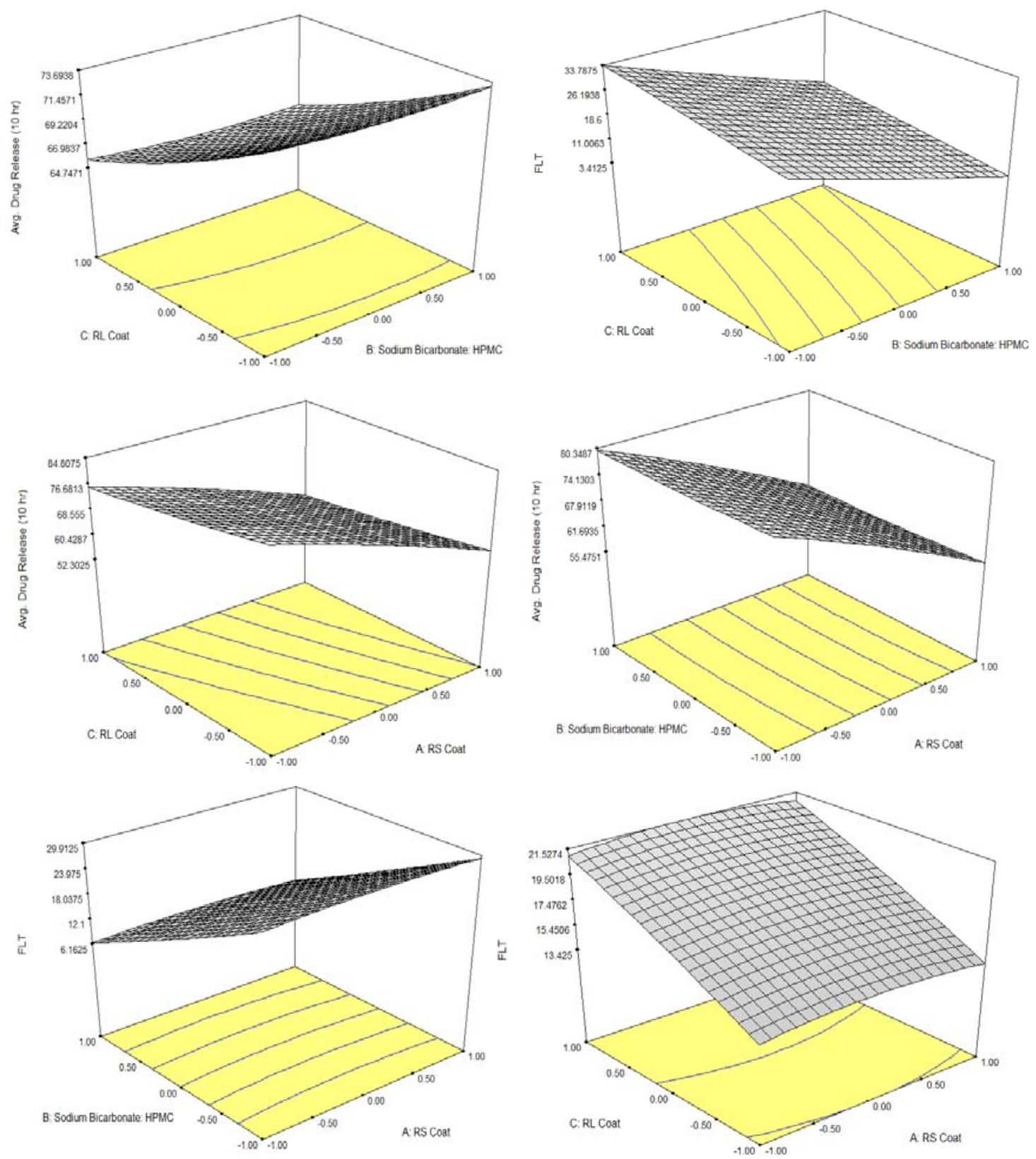

Fig. 5: Response surface plot of floating lag time and average drug release in $10 \mathrm{~h}$ 
Table 7: Summary of statistical parameters for the responses

\begin{tabular}{lll}
\hline Parameter & Floating lag time & Drug release in 10 h \\
\hline Mean & 17.82 & 68.49 \\
SD & 0.21 & 0.36 \\
CV & 1.18 & 0.52 \\
$\mathrm{R}^{2}$ & 0.9997 & 0.9993 \\
Adjusted R $^{2}$ & 0.9994 & 0.9984 \\
Predicted R & 0.9965 & 0.9977 \\
Adeq Precision & 188.959 & 117.944 \\
\hline
\end{tabular}

SD: Standard deviation; CV: Coefficient of variation

The response surface plot obtained for the floating lag time and drug release in $10 \mathrm{~h}$ were indicated in (fig. 5). Response plot of floating lag time indicated a significant effect of the amount of effervescent agent $\left(\mathrm{NaHCO}_{3}: \mathrm{HPMC}\right.$ ratio) and level of gas entrapped polymeric coating (Eudragit RL 100) on floating behaviour. Increasing the amount of effervescent agent and decreasing level of Eudragit RL 100 decreases floating lag time. Eudragit RS 100 significantly affects drug release as shown by response plot of drug release in $10 \mathrm{~h}$. The drug release decrease with increasing level of release retardant Eudragit RS 100 internal coat. The results can be correlated with the obtained regression equation also indicated below (A: Eudragit RS 100; B: $\mathrm{NaHCO}_{3}$ : HPMC and C: Eudragit RL 100). It was observed from regression equation coefficients that (B: $\mathrm{NaHCO}_{3}$ : HPMC) and (C: Eudragit RL 100) had marked negative and positive effect on floating lag time respectively. The regression equation coefficients of average drug release in $10 \mathrm{~h}$ indicated a more pronounced negative effect of
(A: Eudragit RS 100) and (C: Eudragit RL 100) on in vitro drug release.

Regression equations of the fiited quadratic model:

Y1-Floating lag time $=18.10-0.063 \mathrm{~A}-11.48 \mathrm{~B}+3.71 \mathrm{C}-$ $0.64 \mathrm{~A}^{2}+0.34 \mathrm{~B}^{2}-0.29 \mathrm{C}^{2}-0.01 \mathrm{AB}-0.025 \mathrm{AC}-0.45 \mathrm{BC}$

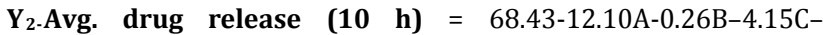
$0.80 \mathrm{~A}^{2}+0.39 \mathrm{~B}^{2}+0.54 \mathrm{C}^{2}-0.028 \mathrm{AB}+0.38 \mathrm{AC}-0.072 \mathrm{BC}$

(fig. 6.) indicating the dignostic plot (predicted vs. actual) for both the responses. It can be seen from the plots that in all the cases there was a reasonable agreement between the predicted and experimental values. This confirms that the selected model for the current study adequately describes the influence of the independent variables on the responses with lower magnitudes of error.
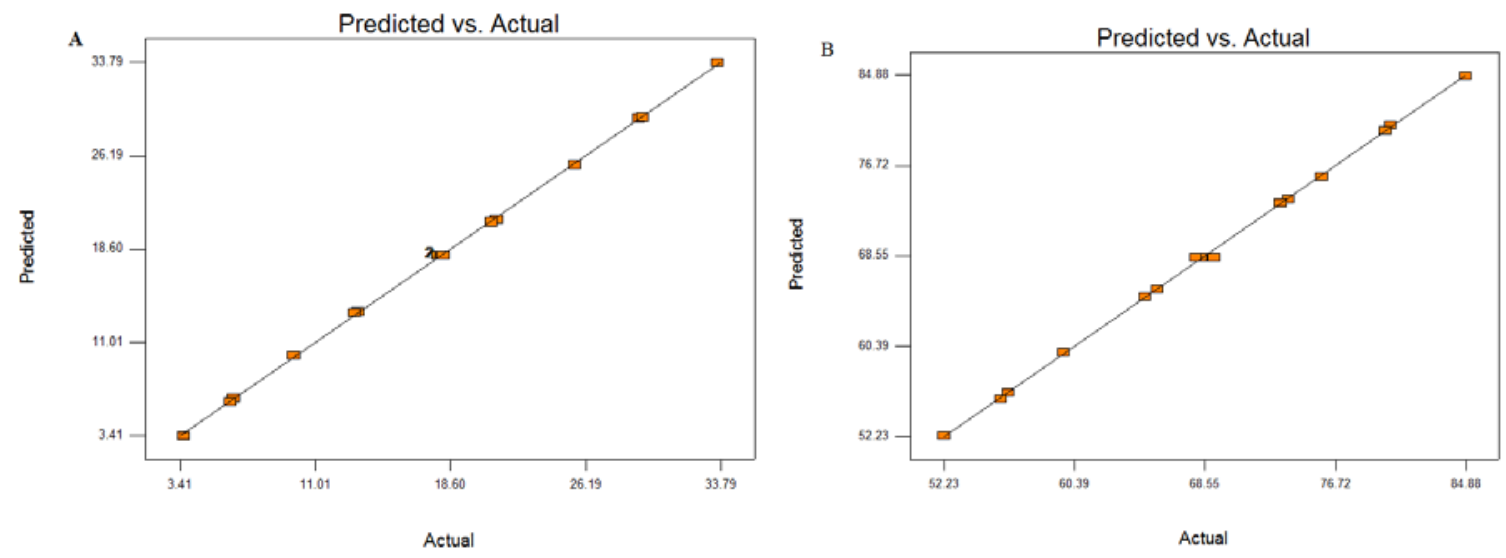

Fig. 6: Correlation between actual and predicted values for (A) Floating lag time and (B) Drug release in $10 \mathrm{~h}$

Desirability approach under numerical optimization technique was used to prepare optimum formulation. The optimum formulation was obtained by applying constraints to independent and dependent variables (responses). Independent variables were kept in the range whereas floating lag time and percent drug release in $10 \mathrm{~h}$ set to minimum and maximum respectively. Nine solutions were generated by the design expert software among which one is selected having the highest desirability. The selected solution is indicated in (table 8). A new optimized formulation (batch F 14) indicated in table 2 was prepared and evaluated for the responses. The results of floating lag time and average drug release obtained of batch F 14 shown in table 4 . The obtained experimental results of batch F 14 were in near proximity to the theoretical values of floating lag time and drug release in $10 \mathrm{~h}$ indicated by numerical optimization (table 8).

Table 8: Summary of numerical optimization

\begin{tabular}{|c|c|c|c|c|}
\hline Parameters & Goal & Solution & Desirability & Remark \\
\hline Independent Variables & & & 1 & Selected \\
\hline Eudragit RL 100 & in range & $-1(5 \%)$ & & \\
\hline $\mathrm{NaHCO}_{3}: \mathrm{HPMC}$ & in range & $+1(2: 1)$ & & \\
\hline Eudragit RL 100 & in range & $-1(5 \%)$ & & \\
\hline \multicolumn{5}{|l|}{ Dependent Variables } \\
\hline Floating lag time & minimum & $3.1 \mathrm{~min}$ & & \\
\hline Percent drug release in $10 \mathrm{~h}$ & maximum & $84.94 \%$ & & \\
\hline
\end{tabular}

\section{Stability studies}

During stability studies, the floating pellet formulation is exposed to the accelerated condition of temperature and humidity for three months. At regular interval $\left(1^{\text {st }}, 2^{\text {nd }}\right.$ and $3^{\text {rd }}$ month), the drug content, drug release at $10 \mathrm{~h}$ and physical appearance were studied. No significant changes in drug content and drug release were observed 
during storage as indicated in (table 9). The physical appearance was also remain unchanged after three month. The data obtained with stability studies indicated that the developed multilayer floating pellet system of anagliptin was stable.

Table 9: Accelerated stability study results for formulation (batch F 14)

\begin{tabular}{llll}
\hline Month & Appearance & Drug Content (\%) & Drug release at 10 h (\%) \\
\hline 0 & White & $98.75 \pm 0.41$ & $86.54 \pm 0.35$ \\
1 & White & $98.24 \pm 1.01$ & $85.49 \pm 0.98$ \\
2 & White & $97.52 \pm 0.95$ & $85.11 \pm 1.12$ \\
3 & White & $96.16 \pm 1.29$ & $84.04 \pm 1.67$ \\
\hline
\end{tabular}

mean $\pm S D ; n=3$

\section{Pharmacokinetics in wistar rats}

The pharmacokinetic parameters were determined for F14 anagliptin floating pellets in comparison to plain anagliptin drug. Anagliptin plasma concentrations comparison between floating pellets and plain drug were shown in (fig. 7). The calculated mean pharmacokinetic parameters were shown in (table 10). The change in Cmax and increase in Tmax values indicated sustained drug release of F14 floating pellets. A 2.51-fold increase in relative bioavailability of F14 anagliptin floating pellets compared to plain drug was observed. Higher half-life, MRT and lower elimination rate constant values indicated long resident time of anagliptin floating pellets. The statistical analysis revealed that there was a significant difference in the Cmax, Tmax, AUC, $\mathrm{t}_{1 / 2}$, Kel and MRT.

Table 10: Pharmacokinetics of anagliptin floating pellets and anagliptin plain drug

\begin{tabular}{lll}
\hline Parameters & F14 anagliptin floating pellets & Anagliptin plain drug \\
\hline $\mathrm{C} \max (\mu \mathrm{g} / \mathrm{ml})$ & $43.17 \pm 2.17^{*}$ & $30.51 \pm 2.83$ \\
$\mathrm{~T} \max (\mathrm{h})$ & $8.00 \pm 0.04^{*}$ & $0.5 \pm 0.04$ \\
$\mathrm{AUC}_{0-\infty}(\mu \mathrm{g}-\mathrm{h} / \mathrm{ml})$ & $376.15 \pm 7.55^{*}$ & $149.86 \pm 6.43$ \\
$\mathrm{MRT}(\mathrm{h})$ & $9.07 \pm 0.03^{*}$ & $4.39 \pm 0.02$ \\
$\mathrm{t}_{1 / 2}(\mathrm{~h})$ & $8.90 \pm 2.43^{*}$ & $4.46 \pm 1.12$ \\
$\mathrm{~K}_{\mathrm{el}}\left(\mathrm{h}^{-1}\right)$ & $0.18 \pm 0.11^{*}$ & $0.37 \pm 0.27$ \\
Relative bioavailability: AUC of F14 Pellets/AUC of Plain drug=2.51 & \\
\hline
\end{tabular}

${ }^{*} \mathrm{P}<0.05$ as compared to anagliptin plain drug, mean $\pm \mathrm{SD} ; \mathrm{n}=6$

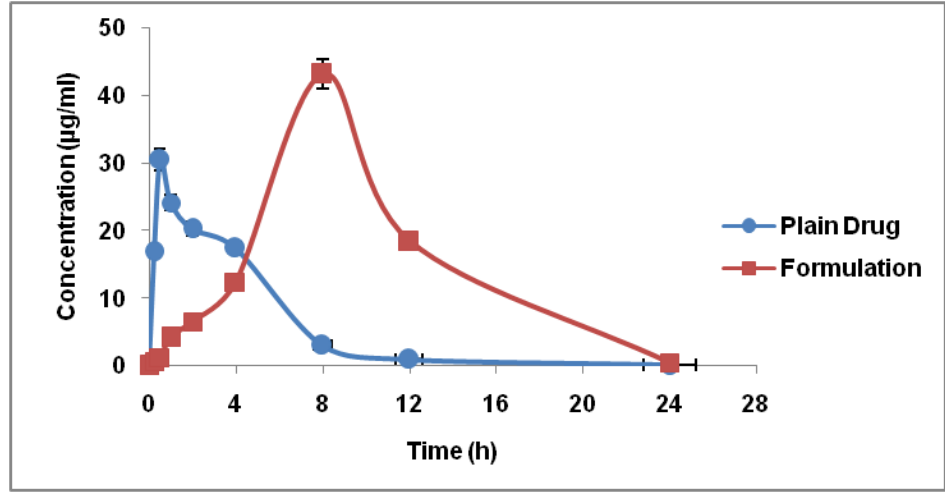

Fig. 7: Time versus mean plasma concentration profiles of anagliptin floating pellets and anagliptin plain drug mean $\pm S D ; n=6$

\section{Pharmacodynamics in Wistar rats}

\section{Effect on calorie intake}

The calorie intake was significantly increased in the cafeteria dietfed rats (3086.05) as compared to the normal diet-fed rats (2108.45). However, the rats received anagliptin floating pellets and orlistat showed a significant decrease in calorie intake per week (2283.99, 1890.18) respectively indicated in (fig. 8).

\section{Effect on body weight and BMI}

The animal group fed with CD for six weeks showed a significant increase in body weight and BMI $(277.98 \pm 3.69,2.65 \pm 0.03)$ compared the normal diet-fed rats $(212.20 \pm 2.63,1.41 \pm 0.04)$ shown in (fig. 9 and 10). Treatment with anagliptin floating pellets and orlistat significantly reduced the increased in body weight and BMI $\quad(238.79 \pm 2.52, \quad 1.96 \pm 0.01) \quad(221.10 \pm 1.44, \quad 1.47 \pm 0.03)$ respectively.

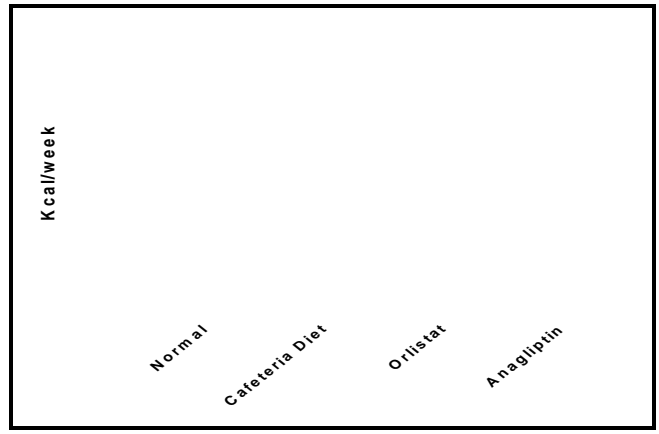

Fig. 8: Effect on calorie intake, values are mean $\pm S E M$, $\mathrm{n}=6,{ }^{\# \#} \mathbf{P}<0.01$ as compared to normal control, ${ }^{* * *} \mathbf{P}<0.001$, ${ }^{*} \mathbf{P}<0.05$ as compared to cafeteria diet group using one way ANOVA followed by Bonferroni test 


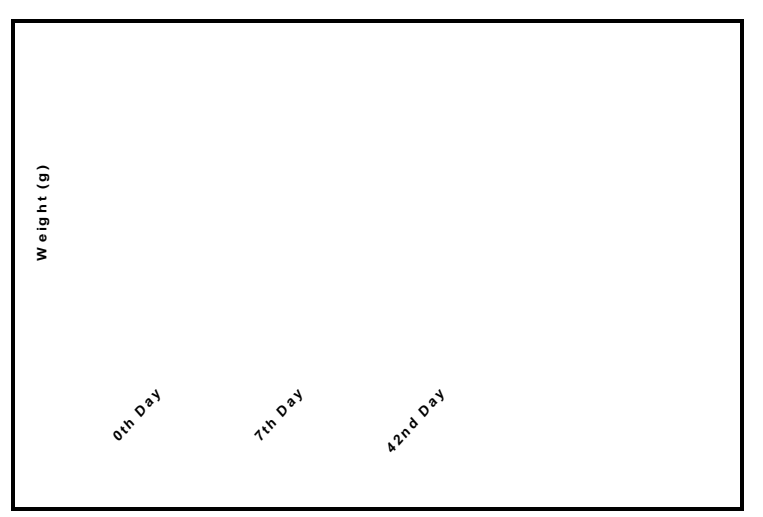

Fig. 9: Effect on body weight, values are mean \pm SEM, $\mathrm{n}=6$, \#\#\#\#P<0.0001 as compared to normal control, ${ }^{* * *} \mathrm{P}<0.001$ as compared to cafeteria diet group on $42^{\text {nd }}$ day using two way ANOVA followed by Bonferroni test

\section{Effect on serum biochemical parameters}

The serum levels of glucose, CH, LDL, TGs, ALT and AST were found to be significantly increased in the cafeteria diet-fed rats compared to the normal diet-fed rats. On the contrary HDL level was found to be significantly decreased in CD control group. However, anagliptin treatment significantly reduced the increase in serum levels of glucose, CH, LDL, TGs, ALT and AST and increased HDL concentration significantly as indicated in (table 11).

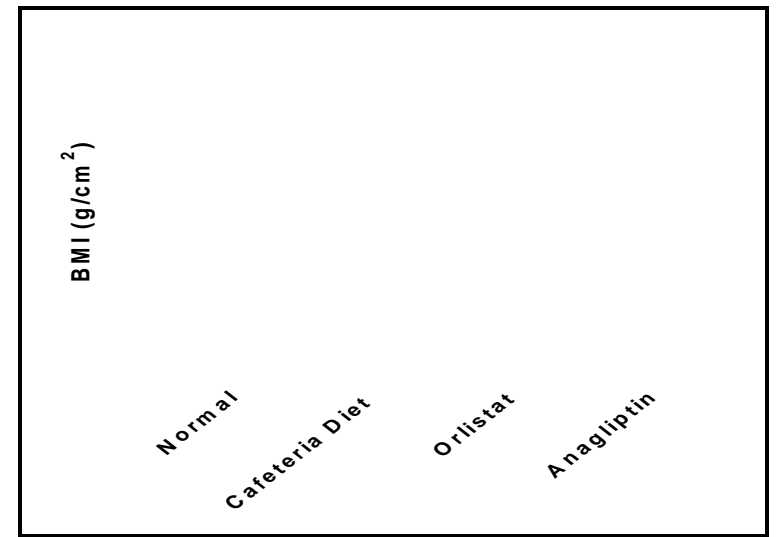

Fig. 10: Effect on $B M I$, values are mean $\pm S E M, n=6$, \#\#\# $P<0.0001$ as compared to normal control, ${ }^{* * *} \mathrm{P}<0.001$ as compared to cafeteria diet group using one way ANOVA followed by bonferroni test

Table 11: Effect of anagliptin treatment on serum biochemical parameters

\begin{tabular}{llll}
\hline Parameters & Normal & Cafeteria Diet & Orlistat \\
\hline Glucose (mg/dl) & $68.89 \pm 0.45$ & $107.13 \pm 0.92^{\# \# \# \#}$ & $80.82 \pm 1.19^{* * *}$ \\
CH (mg/dl) & $66.06 \pm 1.57$ & $110.04 \pm 1.31^{\# \# \# \#}$ & $80.93 \pm 1.51^{* * *}$ \\
LDL (mg/dl) & $37.94 \pm 1.02$ & $55.89 \pm 1.17^{\# \# \#}$ & $39.81 \pm 0.95^{* * *}$ \\
TGs (mg/dl) & $63.95 \pm 0.85$ & $105.99 \pm 1.29^{\# \# \# \#}$ & $75.43 \pm 1.56^{* * *}$ \\
ALT (u/l) & $41.36 \pm 0.63$ & $83.93 \pm 0.41^{\# \# \# \#}$ & $56.19 \pm 0.61^{* *}$ \\
AST ((u/l)) & $58.02 \pm 0.48$ & $103.52 \pm 0.62^{\# \# \# \#}$ & $96.29 \pm 1.31^{* *}$ \\
HDL (mg/dl) & $47.67 \pm 1.45$ & $30.92 \pm 0.77^{\# \# \#}$ & $62.80 \pm 0.69^{* * *}$ \\
\hline
\end{tabular}

Values are mean $\pm \mathrm{SEM}, \mathrm{n}=6,{ }^{*} \# \# \mathrm{P}<0.0001,{ }^{*} \# \mathrm{P}<0.001$ as compared to normal control, ${ }^{* * *} \mathrm{P}<0.001,{ }^{* *} \mathrm{P}<0.01$ as compared to cafeteria diet group.

Table 12: Effect of anagliptin treatment on organs weight

\begin{tabular}{llll}
\hline Organs & Normal & Cafeteria diet & Orlistat \\
\hline Liver (g) & $7.34 \pm 1.15$ & $14.06 \pm 1.24^{\# \# \# \#}$ & $8.25 \pm 1.11^{* * *}$ \\
Heart (g) & $1.22 \pm 0.46$ & $2.70 \pm 0.54^{\# \# \#}$ & $1.68 \pm 0.49^{* * *}$ \\
WAT (g) & $3.65 \pm 0.87$ & $8.48 \pm 1.16^{\# \# \# \#}$ & $4.13 \pm 0.63^{* * *}$ \\
\hline
\end{tabular}

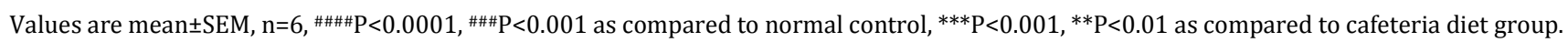

\section{Effect on organ weight and WAT}

The CD control group showed a significant increase in the weight of organs and white adipose tissue as compared to normal control shown in (table 12). Treatment with anagliptin significantly decreased organs weight and white adipose tissue which were induced by cafeteria diet.

\section{CONCLUSION}

The anagliptin gastroretentive floating pellets based on gas formation technique was successfully designed and developed. From the numerical optimization function using Design expert software, an optimal formulation (F 14) comprising of Eudragit RS 100 (5\%), sodium bicarbonate: HPMC (2:1) and Eudragit RL 100 (5\%) was identified. It showed floating lag time of $3.4 \mathrm{~min}$ and $86.54 \%$ drug release at $10 \mathrm{~h}$. The pharmacokinetic study conducted in male Wistar rats showed increased Cmax, prolonged Tmax, half-life and MRT collectively demonstrated sustained drug release. The relative bioavailability of optimized formulation was improved by 2.51 fold in comparison to anagliptin drug. The results of anagliptin floating pellets treatment in male Wistar rats fed on cafeteria diet showed its hypophagic, hypoglycemic and hypolipidemic effects. The gastroretentive floating pellets of anagliptin with improved bioavailability was obtained and could be promisingly used in the management of the metabolic syndrome.

\section{ACKNOWLEDGMENT}

The authors are thankful to Dr. S. S. Chitlange for providing kind support to carry out the research work. The authors acknowledge to Wockhardt Limited, Aurangabad, India and Evonik Pharma, Mumbai, India for providing gift sample of anagliptin and polymethacrylate polymers respectively. Authors are also thankful to Savitribai Phule Pune University for conducting scanning electron microscopic studies.

This research did not receive any specific grant from funding agencies in the public, commercial, or not-for-profit sectors.

\section{AUTHORS CONTRIBUTION}

Both the authors have contributed equally in the research work

\section{CONFLICTS OF INTERESTS}

Declare none

\section{REFERENCES}

1. Van Wormer JJ, Boucher JL, Sidebottom AC, Sillah A, Knickelbine $\mathrm{T}$. Lifestyle changes and prevention of metabolic syndrome in the heart of New Ulm project. Prev Med Rep 2017;6:242-5.

2. Hu G, Qiao Q, Tuomilehto J, Balkau B, Borch-Johnsen K, Pyorala K. Prevalence of the metabolic syndrome and its relation to all- 
cause and cardiovascular mortality in nondiabetic European men and women. Arch Intern Med 2004;164:1066-76.

3. Sattigeri JA, Sethi S, Davis JA, Sahadat A, Rayasam GV, Jadhav $\mathrm{BG}$, et al. Approaches towards the development of chimeric DPP4/ACE inhibitors for treating metabolic syndrome. Bioorg Med Chem Lett 2017;27:2313-8.

4. Mishra RV, Dhole SN. Dipeptidyl peptidase-4 inhibitors: potential for the treatment of metabolic syndrome and developed formulation approaches. Asian J Pharm Clin Res 2017;10:20-6

5. Furuta S, Tamura M, Hirooka H, Mizuno Y, Miyoshi M, Furuta Y. The pharmacokinetic disposition of anagliptin, a novel dipeptidyl peptidase-4 inhibitor, in rats and dogs. Eur J Drug Metab Pharmacokinet 2013;38:87-96.

6. Kagan L, Dreifinger T, Mager D, Hoffman A. Role of Pglycoprotein in region-specific gastrointestinal absorption of talinolol in rats. Drug Metabol Disposition 2010;38:1560-6.

7. Hoffman A, Stepensky D, Lavy E, Eyal S, Klausner E, Friedman M. Pharmacokinetic and pharmacodynamic aspects of gastroretentive dosage forms. Int J Pharm 2004;277:141-53.

8. Streubel A, Siepmann J, Bodmeier R. Gastroretentive drug delivery systems. Expert Opin Drug Delivery 2006;3:217-33.

9. Kagan L, Hoffman A. Systems for region selective drug delivery in the gastrointestinal tract: biopharmaceutical considerations. Expert Opin Drug Delivery 2008;5:681-92.

10. Moes AJ. Gastroretentive dosage forms. Crit Rev Ther Drug Carrier Syst 1993;10:143-95.

11. Kotreka UK, Adeyeye MC. Gastroretentive floating drugdelivery systems: a critical review. Crit Rev Ther Drug Carrier Syst 2011;28:47-99.

12. Reddy LH, Murthy RS. Floating dosage systems in drug delivery. Crit Rev Ther Drug Carrier Syst 2002;19:36.

13. Strusi OL, Sonvico F, Bettini R, Santi P, Colombo G, Barata P, et al. Module assemblage technology for floating systems: in vitro flotation and in vivo gastro-retention. J Controlled Release 2008;129:88-92.

14. Singh BN, Kim KH. Floating drug delivery systems: an approach to oral controlled drug delivery via gastric retention. J Controlled Release 2000;63:235-59.

15. Badve SS, Sher P, Korde A, Pawar AP. Development of hollow/porous calcium pectinate beads for floating-pulsatile drug delivery. Eur J Pharm Biopharm 2007;65:85-93.

16. Ichikawa $M$, Watanabe $S$, Miyake S. A new multiple-unit oral floating dosage system. I: preparation and in vitro evaluation of floating and sustained-release characteristics. J Pharm Sci 1991;80:1062-6.

17. Bulgarelli E, Forni F, Bernabei MT. Effect of matrix composition and process conditions on casein-gelatin beads floating properties. Int J Pharm 2000;198:157-65.

18. Iannuccelli V, Coppi G, Bernabei MT, Cameroni R. Air compartment multiple-unit system for the prolonged gastric residence. Part I. formulation study. Int J Pharm 1998;174:47-54.

19. Streubel A, Siepmann J, Bodmeier R. Multiple units gastroretentive drug delivery systems: a new preparation method for low-density microparticles. J Microencapsul 2003; 20:329-47.
20. Kim SM, Kim JS, Hwang SJ. The effect of sodium alginate on physical and dissolution properties of Surelease matrix pellets prepared by a novel pelletizer. Chem Pharm Bull 2007; 55:1631-4.

21. Parmar SS, Mishra RV, Shirolkar SV. Spherical agglomeration a novel approach for solubility and dissolution enhancement of simvastatin. Asian J Pharm Clin Res 2016;9:65-72.

22. Jaya S, Amala V. Formulation and in vitro evaluation of oral disintegrating tablets of amlodipine besylate. Int J Appl Pharm 2019;11:49-54.

23. Ahmed AA, Wedad KA, Fouad AA. Formulation and evaluation of prochlorperazine maleate sustained release floating tablet. Int J Pharm Pharm Sci 2017; 9:89-98.

24. Raval MK, Ramani RV, Sheth NR. Formulation and evaluation of sustained release enteric-coated pellets of budesonide for intestinal delivery. Int J Pharma Investig 2013;3:203-11.

25. Rajinikanth PS, Karunagaran LN, Balasubramaniam J, Mishra B. Formulation and evaluation of clarithromycin microspheres for the eradication of Helicobacter pylori. Chem Pharm Bull 2008;56:1658-64.

26. Kavita K, Puneeth K, Tamizh T. Development and evaluation of rosiglitazone maleate floating tablets. Int J Appl Pharm 2010;2:6-10.

27. Kauser F, Sadhana S. Development and evaluation of floating tablet of metoprolol succinate for increased bioavailability via in vivo study. Asian J Pharm Clin Res 2018;11:79-84.

28. Costa P, Lobo MS. Modeling and comparison of dissolution profiles. Eur J Pharm Sci 2001;13:123.

29. Ritger PL, Peppas NA. A simple equation for description of solute release. II. Fickian and anomalous release from swellable devices. J Controlled Release 1987;5:37.

30. Lopes CM, Lobo JM, Pinto JF, Costa P. Compressed minitablets as a biphasic delivery system. Int J Pharm 2006;323:93.

31. Korsmeyer RW, Gurny R, Doelkar E, Buri P, Peppas NA. Mechanism of solute release from porous hydrophilic polymers. Int J Pharm 1983;15:25.

32. Higuchi T. Mechanism of sustained action medication: theoretical analysis of rate release of solid drugs dispersed in solid matrices. J Pharm Sci 1963;52:1145-49.

33. Venkata MS, Sreenivasa NR, Ambedkar SS, Janaki BR, Murthyi VR. Statistical design and evaluation of a propranolol $\mathrm{HCl}$ gastric floating tablet. Acta Pharm Sin B 2012;2:60-9.

34. Sahoo J, Murthy PN, Biswal S, Sahoo SK, Mahapatra AK. Comparative study of propranolol hydrochloride release from matrix tablets with Kollidon $\AA S R$ or hydroxypropyl methylcellulose. AAPS PharmSciTech 2008;9:577-82.

35. Kumar S, Alagawadi KR, Raghavendra M. Effect of argyreia speciosa root extract on cafeteria diet-induced obesity in rats. Indian J Pharmacol 2011;43:163-7.

36. Shikova A, Pozharitskayaa O, Makarovaa M, Kovalevaa M, Laaksob I, Damien H, et al. Effect of bergenia crassifolia L. extracts on weight gain and feeding behavior of rats with highcaloric diet-induced obesity. Phytomedicine 2012;19:1250-5.

37. Krogel I, Bodmeier R. Floating or pulsatile drug delivery systems based on coated effervescent cores. Int J Pharm 1999;187:175-84. 